\title{
OPEN Fatty acid desaturase 2 (FADS 2) rs174575 (C/G) polymorphism, circulating lipid levels and susceptibility to type-2 diabetes mellitus
}

\author{
Shilpa S. Shetty ${ }^{1,3} \&$ N. Suchetha Kumari ${ }^{2,3 凶}$
}

Several factors influence an individual's susceptibility in inter-individual lipid changes and its role in the onset of type-2 diabetes mellitus (T2DM). Considering the above fact, the present investigation focuses on determining the association between fatty acid desaturase 2 (FADS2) rs174575 (C/G) polymorphism, circulating lipid levels and susceptibility to type-2 diabetes mellitus. As per the inclusion and exclusion criteria a total of 429 subjects (non-diabetic-216; diabetic-213) were recruited for the study. Glycemic and lipid profile status were assessed using commercially available kits. Based on the previous reports SNP rs 174575 of fatty acid desaturase gene (FADS2) was selected and identified using the dbSNP database. The amplified products were sequenced by means of Sanger sequencing method. Lipid profile status and apolipoprotein levels revealed statistically significant difference between the groups. Three models were assessed namely, recessive model (CC vs CG +GG), dominant model (CC + CG vs GG) and additive model (CC vs CG vs GG). The recessive model, displayed a statistically significant variations between the circulating lipid levels in T2DM. The multivariate model with genotype (G allele carriers), triglyceride (TG) and insulin served as a predictive model. The study results potentiate the functional link between FADS2 gene polymorphism, lipid levels and type-2 diabetes mellitus.

Type 2 diabetes mellitus (T2DM) is referred as an epidemic, increasing at an alarming rate. All around the world, 425 million people present diabetes, and it is estimated to be 629 million in 2045 (IDF Atlas) ${ }^{1}$, including both diagnosed and undiagnosed diabetes. Among the diabetic cases around the globe India secured top position with more than 32 million diabetics, and the number is anticipated to increase up to 79.4 million by $2030^{2}$.

Higher prevalence of diabetes is seen in India when compared to western countries despite lower overweight and obesity rates, suggesting occurrence of diabetes in patients with lower body mass index (BMI) $)^{3,4}$. Hence Indian adults with comparatively lower BMI also poses equal risk as individuals who are obese ${ }^{5,6}$. Joshi SR reported that Asian Indians consists of smaller body size but suffer from central obesity (higher waist to hip ratio) and higher subscapular-to-triceps skin fold ratio when compared with their British counterparts, hence the term thin-fat Indian ${ }^{7}$. Furthermore, it also reflected in triacylglycerol (TG) and higher plasma nonesterified fatty acid (NEFA) concentrations, hyperinsulinemia (with fasting), higher insulin resistance (IR) and post-glucose challenge states ${ }^{7,8}$. Henceforth, in Asian Indians, insulin resistance (IR) is associated with thin-fat unusual body composition ${ }^{7,9}$.

A complicated association exists between type 2 diabetes and dyslipidemia ${ }^{10,11}$ with majority of study revealing insulin resistance primary to varied lipid concentrations ${ }^{12}$, but few studies illustrated that dyslipidemia could be a contributing factor for the pathogenesis of type 2 diabetes ${ }^{13}$ by impairing $\beta$-cell protection or endoplasmic reticulum stress (ER Stress) ${ }^{14,15}$. Complex interactions between nutrients and genes modulate an individual's risk for disease development ${ }^{16}$. Multiple factors governs an individual's lipid levels and their inter-individual differences. The contribution of genetic variability to these differences are still unanswered. Therefore, identification

${ }^{1}$ Central Research Laboratory, K.S.Hegde Medical Academy, Nitte (Deemed To Be University), Deralakatte, Mangalore, India. '2Department of Biochemistry, K.S. Hegde Medical Academy, Nitte (Deemed To Be University), Deralakatte, Mangalore, India. ${ }^{3}$ These authors contributed equally: Shilpa S. Shetty and N. Suchetha Kumari. ${ }^{\square}$ email: kumarin@nitte.edu.in 
of lipid modulating gene variants is critical for understanding the disease pathogenesis. Previous studies have demonstrated the role of fatty acid desaturases in determining the plasma and tissue fatty acid profiles elucidating various molecular pathways of lipid metabolism ${ }^{17,18}$. Further, correlation between fatty acid desaturase (FADS) genetic variants (encoding rate-limiting enzymes for PUFA synthesis) with desaturase activities and blood lipids are also reported ${ }^{19}$. When considering these results it can be concluded that the desaturation pathway appears to be extremely important for lipid homeostasis in the human body. There exist a research gap to explore whether genetic variations of FADS2 would exert effects on circulating lipid levels in type-2 diabetes mellitus ${ }^{19,20}$. The present study aims to find an association between fatty acid desaturase 2 gene polymorphism and circulating lipid levels in type-2 diabetes.

\section{Materials and methods}

The Central Ethics committee of Nitte (Deemed to be University) reviewed and approved the study for human subjects. Informed consent was duly signed after procuring institutional ethical clearance. Subjects were recruited (Non-diabetic-216; Diabetic-213) based on the inclusion and exclusion criteria. The Subjects were recruited according to the ADA criteria ${ }^{21}$. Subjects under the age group of 30-60yrs, both sexes, diagnosed with T2DM atleast 3 months prior screening were included in the study group. All methods were performed in accordance with the relevant guidelines and regulations.

Anthropometric measurements and biochemical estimations. Fasting plasma glucose (FBS), Glycated hemoglobin (HbA1c), and plasma insulin were measured as described previously ${ }^{22}$. Lipid profile status (TC, TG, HDL-C) were analysed using commercially available kits (LiquiCHEK ${ }^{\mathrm{TM}} \mathrm{AGAPPE}$ ). Friedewald formula was used for Low-Density LDL cholesterol (LDL-C) calculation ${ }^{23}$, in subjects with serum TG concentrations $<400 \mathrm{mg} / \mathrm{dL}(4.52 \mathrm{~mol} / \mathrm{L})$. Subjects with serum TG concentrations of $\geq 400 \mathrm{mg} / \mathrm{dL}$ were excluded for LDL-C calculation. ApoA1 and apo B100 were estimated using a commercially available kit (Agape SensIT).

Isolation, quantification of DNA and SNP selection. DNA was isolated using a standardized protocol by Sergeant et $\mathrm{al}^{24}$. The concentration of DNA per sample was determined using bio-spectrophotometer and stored at $-20^{\circ} \mathrm{C}$.

The SNP rs174575 of FADS2 was selected according to previous literature ${ }^{25-28}$ and identified using the dbSNP database ${ }^{29}$ based on the National Centre for Biotechnology Information (NCBI) ${ }^{28}$. The primer pair for SNP rs 174575 (designed for the study) involved in the study was as follows: Forward: AGGCAGATGGACCTG GATTTGA and Reverse TGGCTTGCAAATAGACTCATCTCC. PCR and Sanger sequencing was performed as described previously ${ }^{22}$.

Statistical analysis. SPSS (version 20.0, IBM, Armonk, NY, USA) was used for statistical analysis. The variable between different genotypes were analysed by One-way ANOVA and Bonferroni correction tests. Logistic regression analysis was performed. The discriminative ability of a substantial model with the highest Odds risk (OR) was analysed by receiver operating characteristic (ROC) analysis. $p$ value $<0.05$ was considered to be statistically significant.

\section{Results}

General, anthropometric and biochemical characteristics of the study population. The anthropometric, demographics and glycemic profile of the study population is described previously and has shown a statistically significant difference $(p<0.001)^{22}$.

Among the diabetic group, $93 \%$ of the subjects presented dyslipidemia. Further the pattern of dyslipidemia was studied which displayed that $47.9 \%$ combined type of dyslipidemia (low HDL-C and high TG, high LDL-C and high TG, low HDL-C and high LDL-C), 16.4\% revealed mixed (high LDL-C, TG and low HDL-C) and 28.6\% exposed single type (high LDL-C, high TG and low HDL-C) of dyslipidemia pattern. From the measurements it was noticed that LDL-C (74.20\%) was the most deranged lipid type in the diabetic subject in the present study.

Apo-A1 was lower and ApoB100 levels were higher respectively in the diabetic group and illustrated a high statistical significance $(p<0.001)$ (Table 1$)$. On comparing the apolipoprotein ratio (apoB100/apoA1), the diabetic group showed a higher value than non-diabetic group with high statistical significance.

Correlation between glycemic profile, lipid profile and apolipoproteins in T2DM. The glycemic profile showed positive correlation with lipid profile and apoliporotein status except for HOMA-B and apoA1 (Table 2).

Comparison of the lipid profile in diabetic individuals in different genotype models. CC genotype was wild type homozygote genotype for $\mathrm{rs} 174575 \mathrm{C}>\mathrm{G}$, while GG was homozygous recessive variant. The allele and genotype frequencies have been described previously ${ }^{22}$. Three models were included in this studyAdditive model (CC vs CG vs GG); Dominant model (CC + CG vs GG); Recessive model (CC vs CG + GG) to compare the lipid profile and apolipoprotein levels status with the genotype.

In the additive model, TC, LDL-C and VLDL-C revealed statistically significant difference (Table 3). TC, LDL-C, TG and VLDL revealed statistically significant difference between the groups in the recessive model (Table 3). No statistically significant difference was observed in the dominant model (Table 3). 


\begin{tabular}{|l|l|l|r|}
\hline Parameters $(\mathbf{m g} / \mathbf{d l})$ & Non-diabetic $(\mathbf{N}=\mathbf{2 1 6})$ & Diabetic $(\mathbf{N}=\mathbf{2 1 3})$ & $\boldsymbol{p}$ value \\
\hline TC $^{\star}$ & $164.78 \pm 37.99$ & $211.46 \pm 51.29$ & $<0.001$ \\
\hline TG $^{\star}$ & $120.25(88.92-161.95)$ & $162.00(124.9-218.45)$ & $<0.001$ \\
\hline HDL-C $^{*}$ & $44.14 \pm 19.3$ & $43.38 \pm 15.49$ & 0.786 \\
\hline LDL-C $^{*}$ & $93.71 \pm 43.19$ & $127.84 \pm 48.08$ & $<0.001$ \\
\hline VLDL $^{\star}$ & $24.05(17.784-32.39)$ & $32.00(24.5-42.28)$ & $<0.001$ \\
\hline Apo A & $129.353 \pm 6.064$ & $124.962 \pm 4.466$ & $<0.001$ \\
\hline ApoB100 & $76.401 \pm 1.993$ & $87.340 \pm 4.397$ & $<0.001$ \\
\hline Apo B100/Apo A & $0.592 \pm .035$ & $0.700 \pm 0.046$ & $<0.001$ \\
\hline
\end{tabular}

Table 1. Comparison of the mean lipid profile and apolipoprotein levels in diabetic and non- diabetic individuals. ${ }^{\star} P$ value $\leq 0.05$ was considered statistically significant. ${ }^{*}$ Student $\mathrm{t}$-test, Data are shown as mean \pm SD. ${ }^{*}$ Mann-Whitney $U$ test. Data are shown as median (interquartile range).

\begin{tabular}{|c|c|c|c|c|c|c|c|c|c|c|c|c|c|}
\hline & & HbAlC & TC & TG & HDL-C & LDL-C & VLDL & Insulin & HOMA-IR & HOMA-B & Apo A & Aро B100 & $\begin{array}{l}\text { Apo B100/ } \\
\text { Apo A1 }\end{array}$ \\
\hline \multirow[b]{2}{*}{ FBS (mg/dl) } & Correlation & 0.71 & 0.33 & 0.23 & -0.09 & 0.267 & 0.193 & 0.56 & 0.974 & -0.562 & -0.324 & 0.588 & 0.582 \\
\hline & $\begin{array}{l}\text { Significance } \\
\text { (2-tailed) }\end{array}$ & $<0.001$ & $<0.001$ & 0.072 & $<0.001$ & $<0.001$ & $<0.001$ & $<0.001$ & $<0.001$ & $<0.001$ & $<0.001$ & $<0.001$ & $<0.001$ \\
\hline \multirow[b]{2}{*}{ HbA1C (\%) } & Correlation & & 0.39 & 0.23 & -0.06 & 0.32 & 0.179 & 0.515 & 0.713 & -0.435 & -0.261 & 0.532 & 0.511 \\
\hline & $\begin{array}{l}\text { Significance } \\
\text { (2-tailed) }\end{array}$ & & $<0.001$ & 0.235 & $<0.001$ & $<0.001$ & $<0.001$ & $<0.001$ & $<0.001$ & $<0.001$ & $<0.001$ & $<0.001$ & $<0.001$ \\
\hline \multirow[b]{2}{*}{ TC (mg/dl) } & Correlation & & & 0.352 & 0.052 & 0.867 & 0.341 & 0.424 & 0.374 & -0.256 & -0.204 & 0.386 & 0.378 \\
\hline & $\begin{array}{l}\text { Significance } \\
\text { (2-tailed) }\end{array}$ & & & 0.297 & $<0.001$ & $<0.001$ & $<0.001$ & $<0.001$ & $<0.001$ & $<0.001$ & $<0.001$ & $<0.001$ & $<0.001$ \\
\hline \multirow[b]{2}{*}{ TG (mg/dl) } & Correlation & & & & -0.015 & -0.07 & 0.858 & 0.257 & 0.256 & -0.201 & -0.031 & 0.236 & 0.185 \\
\hline & $\begin{array}{l}\text { Significance } \\
\text { (2-tailed) }\end{array}$ & & & & 0.167 & $<0.001$ & $<0.001$ & $<0.001$ & $<0.001$ & 0.531 & $<0.001$ & $<0.001$ & $<0.001$ \\
\hline \multirow[b]{2}{*}{ HDL-C (mg/dl) } & Correlation & & & & & -0.24 & 0.029 & -0.09 & -0.094 & 0.156 & -0.027 & -0.06 & -0.035 \\
\hline & $\begin{array}{l}\text { Significance } \\
\text { (2-tailed) }\end{array}$ & & & & & 0.567 & $<0.001$ & 0.082 & 0.002 & 0.594 & 0.201 & 0.489 & 0.489 \\
\hline \multirow[b]{2}{*}{ LDL-C (mg/dl) } & Correlation & & & & & & -0.03 & 0.353 & 0.303 & -0.223 & -0.19 & 0.316 & 0.321 \\
\hline & $\begin{array}{l}\text { Significance } \\
\text { (2-tailed) }\end{array}$ & & & & & & $<0.001$ & $<0.001$ & $<0.001$ & $<0.001$ & $<0.001$ & $<0.001$ & $<0.001$ \\
\hline \multirow[b]{2}{*}{ VLDL } & Correlation & & & & & & & 0.24 & 0.219 & -0.187 & -0.043 & 0.215 & 0.174 \\
\hline & $\begin{array}{l}\text { Significance } \\
\text { (2-tailed) }\end{array}$ & & & & & & & $<0.001$ & $<0.001$ & 0.394 & $<0.001$ & $<0.001$ & $<0.001$ \\
\hline \multirow[b]{2}{*}{ Insulin pmol/l } & Correlation & & & & & & & & 0.719 & -0.335 & -0.292 & 0.716 & 0.657 \\
\hline & $\begin{array}{l}\text { Significance } \\
\text { (2-tailed) }\end{array}$ & & & & & & & & $<0.001$ & $<0.001$ & $<0.001$ & $<0.001$ & $<0.001$ \\
\hline \multirow[b]{2}{*}{ HOMA-IR } & Correlation & & & & & & & & & -0.533 & -0.333 & 0.66 & 0.641 \\
\hline & $\begin{array}{l}\text { Significance } \\
\text { (2-tailed) }\end{array}$ & & & & & & & & & $<0.001$ & $<0.001$ & $<0.001$ & $<0.001$ \\
\hline \multirow[b]{2}{*}{ HOMA-B } & Correlation & & & & & & & & & & 0.215 & -0.43 & -0.42 \\
\hline & $\begin{array}{l}\text { Significance } \\
\text { (2-tailed) }\end{array}$ & & & & & & & & & & $<0.001$ & $<0.001$ & $<0.001$ \\
\hline \multirow[b]{2}{*}{ Apo A } & Correlation & & & & & & & & & & & -0.36 & -0.714 \\
\hline & $\begin{array}{l}\text { Significance } \\
\text { (2-tailed) }\end{array}$ & & & & & & & & & & & $<0.001$ & $<0.001$ \\
\hline
\end{tabular}

Table 2. Correlation between glycemic profile, lipid profile and apolipoproteins in type 2 diabetes mellitus. ${ }^{\star} P$ value $\leq 0.05$ was considered statistically significant.

Genotype association (rs174575 (FADS2)) with T2DM. To quantify the relationship between an exposure and a disease, association was measured as odds ratio. Logistic regression, univariate, bivariate and multivariate analysis were performed to identify whether there is any associations between the SNP's , triglycerides, insulin and risk of T2DM. A total of six predictive models for genotype (CG + GG) were studied to assess the association of genotype with T2DM. Three univariate model: Genotype (CG + GG) (model 1), TG (model 2), Insulin (model 3); two bivariate model: genotype and TG (model 4), genotype and insulin (model 5) and one multivariate model including genotype, TG and insulin (model 6) (Fig. 1). 


\begin{tabular}{|c|c|c|c|c|c|c|c|c|c|c|}
\hline \multirow[b]{2}{*}{ Parameters (mg/dl) } & \multicolumn{4}{|c|}{ Additive model (CC vs CG vs GG) } & \multicolumn{3}{|c|}{ Dominant model (CC+CG vs GG) } & \multicolumn{3}{|c|}{ Recessive model (CC+CG vs GG) } \\
\hline & $\mathrm{CC}(\mathrm{N}=180)$ & CG $(\mathrm{N}=29)$ & GG $(N=4)$ & $p$ value & $\mathrm{CC}+\mathrm{CG}(\mathrm{N}=209)$ & GG $(N=4)$ & $p$ value & $\mathrm{CC}(\mathrm{N}=180)$ & $\mathrm{CG}+\mathrm{GG}(\mathrm{N}=33)$ & $p$ value \\
\hline TC & $206.84 \pm 3.73$ & $235.50 \pm 9.35$ & $244.99 \pm 25.02$ & 0.008 & $210.67 \pm 3.48$ & $252.61 \pm 25.59$ & 0.187 & $206.99 \pm 3.69$ & $235.78 \pm 8.68$ & 0.002 \\
\hline TG & $188.97 \pm 9.50$ & $225.59 \pm 23.82$ & $183.39 \pm 63.73$ & 0.107 & $193.99 \pm 8.88$ & $186.46 \pm 65.33$ & 0.899 & $189.46 \pm 9.55$ & $217.84 \pm 22.44$ & 0.041 \\
\hline HDL-C & $45.07 \pm 1.44$ & $43.81 \pm 3.61$ & $42.20 \pm 9.67$ & 0.914 & $44.84 \pm 1.32$ & $44.79 \pm 9.71$ & 0.784 & $44.92 \pm 1.42$ & $44.39 \pm 3.35$ & 0.693 \\
\hline LDL-C & $123.98 \pm 3.54$ & $146.58 \pm 8.89$ & $166.11 \pm 23.77$ & 0.018 & $127.03 \pm 3.29$ & $170.52 \pm 24.20$ & 0.111 & $124.18 \pm 3.52$ & $147.82 \pm 8.27$ & 0.006 \\
\hline VLDL & $36.23 \pm 1.72$ & $44.89 \pm 4.32$ & $27.38 \pm 11.56$ & 0.043 & $37.41 \pm 1.62$ & $28.49 \pm 11.94$ & 0.535 & $36.23 \pm 1.74$ & $42.78 \pm 4.09$ & 0.036 \\
\hline Apo A & $124.86 \pm 0.34$ & $125.26 \pm 0.84$ & $127.34 \pm 2.25$ & 0.514 & $124.89 \pm 0.31$ & $128.37 \pm 2.25$ & 0.287 & $124.83 \pm 0.33$ & $125.66 \pm 0.78$ & 0.444 \\
\hline Apo B100 & $87.51 \pm 0.33$ & $86.59 \pm 0.83$ & $85.27 \pm 2.21$ & 0.381 & $87.38 \pm 0.30$ & $85.23 \pm 2.24$ & 0.346 & $87.49 \pm 0.33$ & $86.50 \pm 0.77$ & 0.203 \\
\hline Apo B100/A1 & $0.70 \pm 0.003$ & $0.69 \pm 0.01$ & $0.67 \pm 0.02$ & 0.250 & $0.70 \pm 0.003$ & $0.663 \pm 0.024$ & 0.191 & $0.70 \pm 0.003$ & $0.69 \pm 0.01$ & 0.162 \\
\hline
\end{tabular}

Table 3. Comparison of lipid profile and apolipoprotein levels between the diabetic individuals using different genotype models. ${ }^{\star} P$ value $\leq 0.05$ was considered statistically significant.

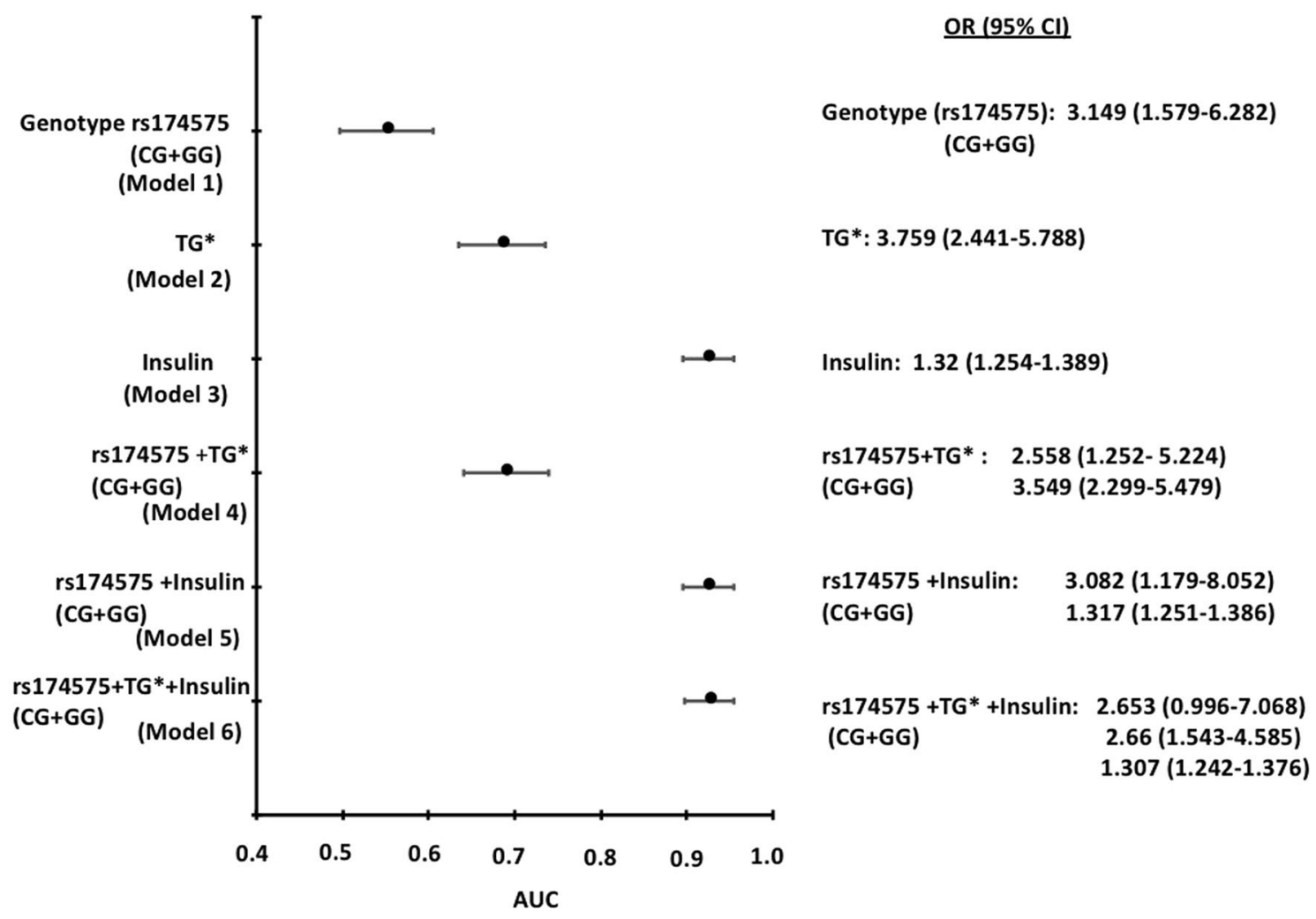

Figure 1. : Predictive models for association of FADS 2 (rs174575) and risk of T2DM.

The results of univariate analysis showed that rs 174575 of the FADS 2 gene showed an odds risk (OR) of 3.149 (95\% CI 1.579-6.282) (Model 1), TG showed an odds risk (OR) of 3.759 (95\% CI 2.441-5.788) (Model 2) and insulin showed an odds risk (OR) of 1.32 (95\% CI 1.32 (1.254-1.389) (Model 3). In the bivariate model rs 174575 and TG showed an OR of 2.558 (95\% CI 1.252-5.224); 1.317 (95\% CI 1.251-1.386) and rs 174575 and insulin showed an OR of 3.082 (95\% CI 1.179-8.052); 1.317 (95\% CI 1.251-1.386). In the multivariate model rs 174575, TG and insulin showed an OR of 2.653 (95\% CI 0.996-7.068); 2.66 (95\% CI 1.543-4.585); 1.307 (95\% CI1.242-1.376).Area under the curve (AUC) (X-axis in Fig. 1) depicts the accuracy of the measurement of a test i.e., an area of $0.9-1$ represents a perfect test; an area of $0.5-0.7$ is no better than chance. Therefore, model $1(\mathrm{AUC}=0.55)$, model $2(\mathrm{AUC}=0.685)$ and model $4(\mathrm{AUC}=690)$ showed $\mathrm{AUC} \leq 0.7$ therefore the association may be by chance. However, model $3(\mathrm{AUC}=0.925)$, model $5(\mathrm{AUC}=0.925)$ and model $6(\mathrm{AUC}=0.926)$ showed and AUC $>0.9$ suggesting perfect association with T2DM risk (Fig. 1).

\section{Discussion}

Diabetic populations are also prone to lipid and lipoprotein abnormalities as an indirect effect of insulin resistance on key metabolic enzymes ${ }^{30}$. Effect of lipid levels with glucose levels is previously studied and is very well established ${ }^{30,31}$. Carbohydrates and lipid metabolism are interrelated to each other ${ }^{30,31}$. Our present investigation demonstrated significantly increased levels of total cholesterol (TC) in diabetic patients, with $56.4 \%$ having 
cholesterol levels above $200 \mathrm{mg} / \mathrm{dl}$. This increase in TC can be due to the increased hepatic VLDL production or reduced removal of circulating VLDL and LDL-C ${ }^{32}$. It is evident from the present investigation that, VLDL and LDL-C increased in diabetic individuals. The diabetic subjects had a higher level of triglycerides (TG). About $58.7 \%$ of the diabetic subjects had triglyceride levels above $150 \mathrm{mg} / \mathrm{dL}$. Elevated levels of triglycerides elevate free fatty acid level, which may in turn induce insulin resistance and $\beta$-cell dysfunction ${ }^{31}$. The elevated free fatty acid levels, in turn, impairs normal function of the $\beta$-cell by disrupting or modulating the cascade that links insulin receptors with glucose transporters ${ }^{33}$.

The study also showed a significantly increased level of LDL-C in diabetic patients. About $74.2 \%$ of the diabetic subjects had LDL-C levels more than $100 \mathrm{mg} / \mathrm{dL}$ of which $8.5 \%$ showed LDL levels of $190 \mathrm{mg} / \mathrm{dL}$. LDL-C was the most prevalent type of lipid abnormality observed in the current study. This may be attributed to the higher insulin levels in the study. The number of LDL-C receptors depends on insulin and reduced levels of LDL-C receptors can be associated with chronic deficiency of insulin ${ }^{34}$. Therefore, in type-2 diabetic individuals, insulin increases in the bloodstream, due to insulin resistance, which in turn increases the LDL-C particles thereby increasing the LDL-C levels.

HDL-C pays a direct role in glucose metabolism. The study observed a decreased HDL-C levels in diabetic subjects than normal levels. TG enrichment by Cholesteryl ester transfer protein (CTEP) and increased hepatic triglyceride lipase activity, in turn, results in lowered HDL-C. The liver produces HDL-C particle. In the diabetic state, this metabolic pathway will be defective, hence limiting the HDL-C production from the source. Low HDL-C, low anti-inflammatory activity and reduced reverse cholesterol transport, altering microenvironment, increased insulin resistance and impaired $\beta$-cell function ${ }^{34}$.

Apo A1 is antiatherogenic ${ }^{35}$. In the present study, apoA1 was lower in diabetic this was not in accordance with the previous report ${ }^{36}$. Whereas apoB100 is atherogenic ${ }^{37}$. According to the previous studies, apo-B represents an ideal marker for the management of dyslipidemia in individuals with diabetes ${ }^{38-40}$. The apoB100/apoA1 ratio indicates antiatherogenic and atherogenic balance; the higher the value, higher the CV risk. On comparing the apolipoprotein ratio (apoB100/apo A1), the diabetic group showed a higher value than that of the non-diabetic group. The apoB100/apoA1 ratio is strongly associated with insulin resistance. In the current study, on analyzing the pattern of dyslipidemia in diabetic subjects, about $47.9 \%$ is due to the combined type of dyslipidemia followed by single and mixed type. Desaturation and elongation are steps of a metabolic pathway in which dietary and endogenous saturated fatty acids (SFAs) are lengthened and converted to mono-unsaturated fatty acids (MUFA), and highly polyunsaturated fatty acid (PUFA) are synthesized from dietary n-6 fatty acids (e.g., linoleic acid) and n-3 fatty acids (e.g., $\alpha$-linolenic acid) in the liver and adipose tissue Fatty acid desaturase inset unsaturated bonds to fatty acid molecules. Previous studies have shown that even a single nucleotide polymorphisms (SNPs) in FADS genes are associated with not only altered fatty acid desaturase activity but has also shown profound changes in lipid profile status ${ }^{41}$. Allele frequencies and genotype frequencies are the two fundamental calculations of population genetics ${ }^{42}$. The minor allele frequency in the study subject was above 0.05 (i.e., 0.08 in non-diabetic and 0.09 in diabetic). All of the associated SNPs are intronic or intergenic variants, and there are scarce reports on exonic coding variants in the FADS genes ${ }^{43}$. The CC homozygote is the wildtype, CG is the heterozygote, and GG is the recessive variant. The frequency of occurrence of ' $G$ ' allele carriers were higher in diabetic individuals. Of the three genotype models deduced to study the relationship between genotype and the clinical characteristics, the recessive model (CC vs CG + GG) showed a statistically significant result. TC, LDL-C, TG and VLDL showed a statistical difference between the groups. From the study findings, the multivariate model with Genotype, TG and Insulin model showed an association between genotype and type-2 diabetes risk. Based on the odds risk values genotype itself showed a threefold higher association with diabetes i.e., the minor $\mathrm{G}$ allele carriers are the risk group. In the present study since the population size is small, insulin and TG add value to the model. Based on the study results a suggestive mechanism elucidating the association between FADS 2 gene polymorphism and lipid levels and type-2 diabetes susceptibility is as follows: FADS 2 gene encodes for the enzyme delta- 6 desaturase which is a rate-limiting enzyme in polyunsaturated fatty acids (PUFA) metabolism. FADS 2 minor alleles were associated with decrease enzyme activity and therefore less conversion of precursors to products ${ }^{44}$.

From the literature it is evident that FADS 2 SNPs interact with genes such as PPAR- $\gamma$ which in turn is closely associated with IR, Mets and DM ${ }^{45}$. PPAR- $\gamma$ acts as a dominant regulator of adipogenesis and plays an important role in lipogenesis ${ }^{45}$. Ligands of PPAR- $\gamma$ may be biological or synthetic. The synthetic ligands include thiazolidinedion (TZD) (anti-diabetic drug) and fibrates (hyperlipidimic) whereas biological ligands are PUFA's, prostanoids, leukotrienes etc. From this a suggestive mechanism of action of minor allele carriers as derived from the study is that the minor allele carriers show altered PUFA metabolism wih omega 3 fatty acids and increased LA (from dietary major sources such as seed oils) and AA, accumulation, activates NF-Kappa B, transcribing COX and lipo-oxygenese genes and increasing inflammation, reduce insulin sensitivity and increased insulin resistance which in turn results in increasing HSL activity which hydrolysis TG to glycerol and free fatty acids (FFA) which in turn is released to the circulation in blood and moves towards the liver. Once the triglycerides are in the circulation, carried by VLDL, the cholesterol ester from HDL is transferred to the VLDL, and the triglycerides leave the VLDL and replace the cholesterol ester in HDL. The newly formed VLDL is exchanged for the cholesterol ester in LDL, forming small, dense, LDL. The bidirectional transfer of triglyceride leads to elevated triglyceride levels. The removal of the cholesterol ester from HDL makes HDL very susceptible to breakdown and excretion resulting in a reduction of HDL levels (Fig. 2). Further elucidation of mechanistic studies with cell and knockout mice models might add value to the study results. 


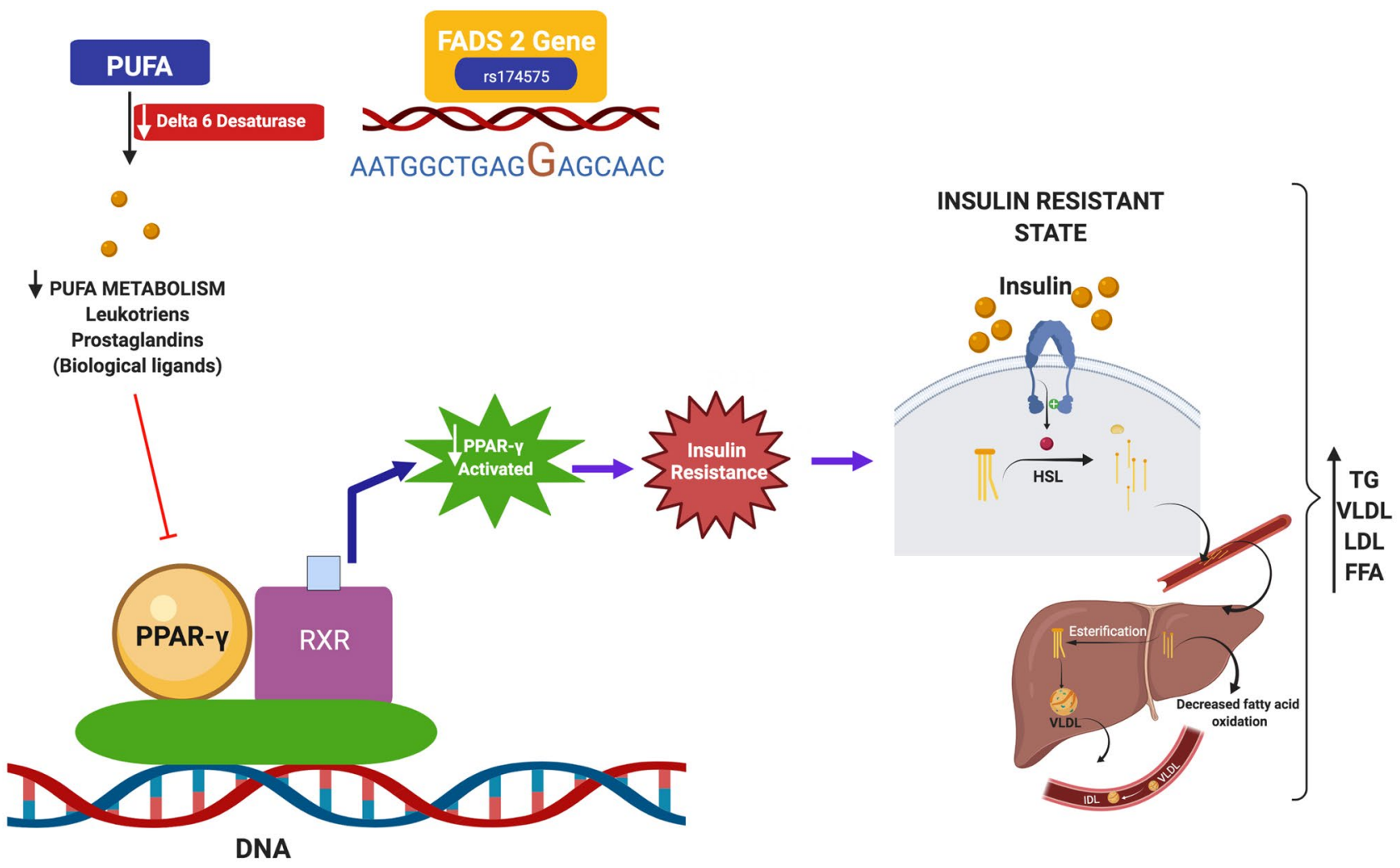

Figure 2. Proposed mechanism showing association between FADS 2 gene polymorphism, lipid levels and type-2 diabetes mellitus.(Created with BioRender.com)

\section{Conclusion}

From the obtained results it is confirmed that there exists a functional link between fatty acid desaturase gene polymorphism and lipid profile ststus in type-2 diabetes mellitus. Further research on how fatty acid desaturases exert its effect on triglyceride levels needs to be enumerated. This will provide a wide insight into the effect of fatty acid desaturases on human health and disease. Further this might lead to the development of fatty acid desaturase activity based personalized therapeutic strategies.

Received: 23 February 2021; Accepted: 2 June 2021

Published online: 23 June 2021

\section{References}

1. International Diabetes Federation. 8th. Brussels, Belgium: International Diabetes Federation; 2017. http://www.diabetesatlas.org.

2. Mohan, D. et al. Awareness and knowledge of diabetes in Chennai-the Chennai Urban Rural Epidemiology Study [CURES-9]. Assoc. Phys India 53, 283-287 (2005).

3. Rao, C. R., Kamath, V. G., Shetty, A. \& Kamath, A. A cross-sectional analysis of obesity among a rural population in coastal southern Karnataka, India. Australas. Med. J. 4(1), 53-57 (2011).

4. Mohan, V. \& Deepa, R. Obesity and abdominal obesity in Asian Indians. Indian J. Med. Res. 123(5), 593-596 (2006).

5. Zargar, A. H. et al. Prevalence of type 2 diabetes mellitus and impaired glucose tolerance in the Kashmir Valley of the Indian subcontinent. Diabetes Res. Clin. Pract. 47(2), 135-146 (2000).

6. Misra, A. \& Khurana, L. Obesity-related non-communicable diseases: South Asians vs White Caucasians. Int. J. Obes. (Lond.) 35(2), 167-187 (2011).

7. Joshi, S. R. Diabetes care in India. Ann. Glob. Health 81(6), 830-838 (2015).

8. Deurenberg, P., Deurenberg-Yap, M. \& Guricci, S. Asians are different from Caucasians and from each other in their body mass index/body fat per cent relationship. Obes. Rev. 3, 141-146 (2002).

9. McKeigue, P. M., Shah, B. \& Marmot, M. G. Relation of central obesity and insulin resistance with high diabetes prevalence and cardiovascular risk in South Asians. Lancet 337, 382-386 (1991).

10. Adiels, M., Olofsson, S. O., Taskinen, M. R. \& Boren, J. Diabetic dyslipidemia. Curr. Opin. Lipidol. 17(238-246), 2 (2006).

11. Mooradian, A. D. Dyslipidemia in type 2 diabetes mellitus. Nat. Clin. Pract. Endocrinol. Metab. 5, 150-159 (2009).

12. Kruit, J. K., Brunham, L. R., Verchere, C. B. \& Hayden, M. R. HDL and LDL cholesterol significantly influence beta-cell function in type 2 diabetes mellitus. Curr. Opin. Lipidol. 21, 178-185 (2010).

13. Pétremand, J. et al. HDLs protect pancreatic $\beta$-cells against ER stress by restoring protein folding and trafficking. Diabetes 61(5), 1100-1111 (2012 May)

14. Fall, T. et al. Using genetic variants to assess the relationship between circulating lipids and type 2 diabetes. Diabetes 64, 2676-2684 (2015).

15. Samatha, P., Venkateswarlu, M. \& Siva, P. V. Lipid profile levels in type 2 diabetes mellitus from tribal population of Adilabad in Andhra Pradesh, India. J. Clin. Dia Res. 6(4), 590-592 (2012). 
16. Lairon, D. et al. Nutrigenetics: links between genetic background and response to Mediterranean-type diets. Public Health Nutr. 12(9A), 1601-1606 (2009).

17. Huang, M. C. et al. FADS gene polymorphisms, fatty acid desaturase activities, and HDL-C in type 2 diabetes. Int. J. Environ. Res. Public Health 14(6), 572 (2017 May 28).

18. Brayner, B., Kaur, G., Keske, M. A. \& Livingstone, K. M. FADS polymorphism, omega-3 fatty acids and diabetes risk: A systematic review. Nutrients 10(6), 758 (2018 Jun 13).

19. Huang, M. C. et al. FADS2 polymorphisms correlate with HDL-C and desaturase activity in type 2 diabetes. Int. J. Environ. Res. Public Health 14(6), 572 (2017).

20. Lipid homeostasis. Science direct [Internet]. [Cited 2019, July 20]. https://www.sciencedirect.com/topics/medicine-and-dentistry/ lipid-homeostasis.

21. American Diabetes Association. Standards of medical care in diabetes--2014. Diabetes Care. 2014 Jan; 37 Suppl 1:S14-80. https:// doi.org/10.2337/dc14-S014. PMID: 24357209.

22. Shetty, S. S., Suchetha, K. N., Devi, H., Sharmila, K. P. \& Rai, S. Association of FADS2 rs174575 gene polymorphism and insulin resistance in type 2 diabetes mellitus. Afr. Health Sci. 20(4), 1770-1776 (2020).

23. Krauss-Etschmann, S. et al. Effects of fish-oil and folate supplementation of pregnant women on maternal and fetal plasma concentrations of docosahexaenoic acid and eicosapentaenoic acid: A European randomized multicenter trial. Am. J. Clin. Nutr. 85, $1392-1400$ (2007).

24. Sergeant, S. et al. Differences in arachidonic acid levels and fatty acid desaturase (FADS) gene variants in African Americans and European Americans with diabetes or the metabolic syndrome. Br. J. Nutr. 107(4), 547-555 (2012)

25. Kinsell, L. W., Walker, G., Michaels, G. D. \& Olson, F. E. Dietary fats and the diabetic patient. N. Engl. J. Med. 261(431-434), 200-204 (1959).

26. Krauss-Etschmann, S. et al. Effects of sh-oil and folate supplementation of pregnant women on maternal and fetal plasma concentrations of docosa- hexaenoic acid and eicosapentaenoic acid: A European randomized multicenter trial. Am. J. Clin. Nutr. 85, 1392-1400 (2007).

27. Koletzko, B., Demmelmair, H., Schaeffer, L. \& Illig, Heinrich J. Genetically determined variation in polyun-saturated fatty acid metabolism may result in different dietary requirements. Nestle Nutr. Workshop Ser. Pediatr. Program 62, 35-49 (2008),

28. National Center for Biotechnology Information (NCBI) Internet. Bethesda (MD): National Library of Medicine (US), National Center for Biotechnology Information; 1988-cited 2017 Apr 06. https://www.ncbi.nlm.nih.gov/.

29. Steer, C. D., Davey Smith, G., Emmett, P. M., Hibbeln, J. R. \& Golding, J. FADS2 polymorphisms modify the effect of breastfeeding on child IQ. PLoS One 5(7), 256-257 (2010).

30. Parhofer, K. G. Interaction between glucose and lipid metabolism: More than diabetic dyslipidemia. Diabetes Metab. J. 39(5), 353-362 (2015).

31. Khadke, S. et al. Association of fasting plasma glucose and serum lipids in type 2 diabetics. Indian J. Pharm. Sci. 77(5), 630-634 (2015).

32. Ganong, W. F. Review of medical physiology. In Endocrine Function of pancreas \& Regulation of Carbohydrate Metabolism;2003

33. Feingold, K. R. Introduction to Lipids and Lipoproteins. [Updated 2021 Jan 19]. In: (eds. Feingold, K.R. et al.). Endotext [Internet]. South Dartmouth (MA): MDText.com, Inc.; 2000-. Available from: https://www.ncbi.nlm.nih.gov/books/NBK305896/

34. Hirano, T. Pathophysiology of diabetic dyslipidemia. J. Atheroscler. Thromb. 25(9), 771-782 (2018).

35. Scharnagl, H. \& Marz, W. New lipid-lowering agents acting on LDL receptors. Curr. Top. Med. Chem. 5, 233 (2005).

36. Onat, A. et al. The paradox of high apolipoprotein A-I levels independently predicting incident type-2 diabetes among Turks. Int. J. Cardiol. 142, 72 (2010).

37. Walldius, G. \& Jungner, I. Apolipoprotein A-I versus HDL cholesterol in the prediction of risk for myocardial infarction and stroke. Curr. Opin. Cardiol. 22, 359 (2007).

38. Barkas, F., Elisaf, M., Liberopoulos, E., Liontos, A. \& Rizos, E. C. High triglyceride levels alter the correlation of apolipoprotein B with low- and non-high-density lipoprotein cholesterol mostly in individuals with diabetes or metabolic syndrome. Atherosclerosis 247, 58-63 (2016).

39. Boden, G. Obesity, insulin resistance and free fatty acids. Curr. Opin. Endocrinol. Diab Obes. 18(2), 139-143 (2011).

40. Hwang, Y. C., Ahn, H. Y. \& Kim, W. J. Increased apoB/A-I ratio independently associated with type 2 diabetes mellitus: crosssectional study in a Korean population. Diabet. Med. 29, 1165 (2012).

41. Czumaj, A. \& Śledziński, T. Biological role of unsaturated fatty acid desaturases in health and disease. Nutrients 12(356), 1-25 (2020).

42. Kim, O. Y., Lim, H. H., Yang, L. I., Chae, J. S. \& Lee, J. H. Fatty acid desaturase (FADS) gene polymorphism and insulin resistance in association with serum phospholipid polyunsaturated fatty acid composition in healthy Korean men: Cross-sectional study. Nutr. Metab. 8, 24 (2011).

43. Cormier, H. et al. Polymorphism in fatty acid desaturase (FADS) gene cluster: Effects on glycemic controls following an omega-3 polyunsaturated fatty acids (PUFA) supplementation. Genes 4, 485-498 (2013).

44. Steer, C. D., Davey Smith, G., Emmett, P. M., Hibbeln, J. R. \& Golding, J. FADS2 polymorphisms modify the effect of breastfeeding on child IQ. PLoS ONE 5(7), 1157 (2010).

45. Moseti, D., Regassa, A. \& Kim, W. K. Molecular regulation of adipogenesis and potential anti-adipogenic bioactive molecules. Int. J. Mol. Sci. 17(1), 124 (2016).

\section{Author contributions}

Corresponding Author: Dr. N.S.K.: Conceptualization, Methodology, Validation, Supervision. First Author: Dr. S.S.S.: Conceptualization, Methodology, formal analysis, investigation, data curation, writing-original draft, reviewing, editing, visualization.

\section{Competing interests}

The authors declare no competing interests.

\section{Additional information}

Correspondence and requests for materials should be addressed to N.S.K.

Reprints and permissions information is available at www.nature.com/reprints.

Publisher's note Springer Nature remains neutral with regard to jurisdictional claims in published maps and institutional affiliations. 
(c) (i) Open Access This article is licensed under a Creative Commons Attribution 4.0 International cc) License, which permits use, sharing, adaptation, distribution and reproduction in any medium or format, as long as you give appropriate credit to the original author(s) and the source, provide a link to the Creative Commons licence, and indicate if changes were made. The images or other third party material in this article are included in the article's Creative Commons licence, unless indicated otherwise in a credit line to the material. If material is not included in the article's Creative Commons licence and your intended use is not permitted by statutory regulation or exceeds the permitted use, you will need to obtain permission directly from the copyright holder. To view a copy of this licence, visit http://creativecommons.org/licenses/by/4.0/.

(C) The Author(s) 2021 